\title{
Talc-induced inflammation in the pleural cavity
}

\author{
M.M. van den Heuvel*, H.J.M. Smit', S.B. Barbierato*, C.E.G. Havenith*, \\ R.H.J. Beelen*, P.E. Postmus
}

Talc-induced inflammation in the pleural cavity. M.M. van den Heuvel, H.J.M. Smit, S.B. Barbierato, C.E.G. Havenith, R.H.J. Beelen, P.E. Postmus. OERS Journals Ltd 1998.

ABSTRACT: Talc administration into the pleural cavity induces pleurodesis. To obtain further insight into the inflammatory process that causes pleurodesis, the cellular kinetics in the pleural space after the administration of talc was studied, along with its relation to chemokine concentrations in the pleural fluid.

Thirteen consecutive patients with idiopathic spontaneous pneumothorax and eight patients with malignant pleural effusions received talc pleurodesis. The first group was treated with talc poudrage, whereas the second group was treated with talc slurry. Pleural fluids were isolated before talc administration as well as 3, 6, 24, 48 and $72 \mathrm{~h}$ afterwards.

The talc induced a rapid polymorphonuclear neutrophil (PMN) influx followed by an accumulation of macrophages. In addition, increased production of interleukin (IL)-8 and monocyte chemotactic protein (MCP)-1 was observed. The talc-induced PMN influx reached its maximum after 3-24 h, and was related to the IL-8 concentration. In contrast, the MCP-1 was not related to the macrophage accumulation.

Talc-induced inflammation in patients with idiopathic spontaneous pneumothorax and malignant pleural effusion is characterized by an influx of polymorphonuclear neutrophils related to interleukin-8, followed by an accumulation of monocytes. Eur Respir J 1998; 12: 1419-1423.

*Dept of Cell Biology and Immunology, Faculty of Medicine of Free University, Amsterdam, The Netherlands. ثDept of Pulmonary Medicine, Free University Hospital, Amsterdam, The Netherlands.

Correspondence: M.M van den Heuvel, Dept of Cell Biology and Immunology, Faculty of Medicine, Free University, Van de Boechorststraat 7, 1081 BT Amsterdam, The Netherlands, Fax: 31204448081

Keywords: Chemokines

human

inflammation

pleurodesis

Received: March 241998

Accepted after revision August 91998

Supported in part by the Dutch Asthma Foundation (NAF 32.94.37).
Chemical pleurodesis is a therapeutic method often used to prevent pleural fluid accumulation in patients with malignant pleural effusion (MPE). Chemical pleurodesis can also be indicated in patients with idiopathic spontaneous pneumothorax (ISP) [1]. Pleurodesis can be induced by chemical irritation with agents such as bleomycin, tetracycline and talc. A variety of other agents have been used with different success rates [2]. In many clinics, talc has become the preferred agent for the treatment of MPE [3]. Talc can be applied as dry powder by insufflation or dissolved in saline (talc slurry). To administer dry talc powder, thoracoscopy is required, while tale slurry can be applied via a chest tube. Both methods appear to be effective in creating pleurodesis $[4,5]$.

Discussion of the choice of sclerosating agent is hampered by the lack of knowledge of the inflammatory process. It is assumed that the sclerosating agents induce an inflammatory response that results in a rapid adhesion of the parietal and visceral pleura. In the literature, only scarce information is available on the inflammatory mechanism itself. In a rabbit model, talc administration induced an influx of polymorphonuclear neutrophils (PMN) followed by an accumulation of mononuclear cells [6]. Several chemokines have been implicated in leukocyte chemotaxis during the inflammatory response [7, 8]. The most studied chemokines for PMN and monocytes are interleukin (IL)-8 and monocyte chemotactic protein (MCP)-1, respectively. In malignant pleural effusions, the concentrations of these chemokines were found to be related to cell indices [9].
To obtain a better understanding of the process of pleurodesis, it is necessary to study the preceding induced inflammation in the pleural cavity [10]. Therefore, a study was designed in which cellular changes in the pleural fluid of patients undergoing talc pleurodesis could be monitored over time, and the cellular kinetics related to the concentrations of IL-8 and MCP-1.

\section{Materials and methods}

\section{Study subjects}

The pleural fluids of 13 consecutive patients with an ISP and eight patients with an MPE were analysed during the period September 1996 to April 1997. All patients gave informed consent. None of the patients had been previously treated for pleural disease or had undergone invasive diagnostic procedures for pleural disease, other than pleurocentesis.

The 13 ISP patients (aged 35 \pm 8 yrs, 12 males) underwent video-assisted thoracoscopy (VAT), under local anaesthesia, with the administration of $3 \mathrm{~g}$ of dry talc powder as soon as possible after admittance to the hospital, as is the routine treatment. The mean time between the first complaints and the pleurodesis was 5.5 \pm 2.9 days for ISP. Four patients received a chest tube for $1.4 \pm 1.0$ days before the VAT procedure.

Of the eight MPE patients (aged 56 \pm 9 yrs, 3 males), two had breast cancer, four nonsmall cell lung cancer and two ovarian cancer. Pleurodesis was performed by injecting $50 \mathrm{~mL}$ of slurry containing $3 \mathrm{~g}$ of talc into the chest 
tube. Drain production had to be $<100 \mathrm{~mL} \cdot$ day $^{-1}$ before pleurodesis was performed. The mean drainage time prior to pleurodesis was $7.2 \pm 5.2$ days.

\section{Study design and methods}

Pleural fluid samples were collected immediately before pleurodesis and after 3, 6, 24, 48 and $72 \mathrm{~h}$. In most ISP patients and some MPE patients, the sampling was performed by a pleural lavage with $<40 \mathrm{~mL}$ of saline during VAT or through the chest tube.

To gain insight into the influence of the chest tube on the cellular composition and the cell number in the pleural fluid, a pilot experiment was designed in which pleural fluid samples of six ISP patients were collected immediately after chest installation and just before talc administration, during the VAT procedure. The mean time between chest tube installation and VAT was $34 \pm 9 \mathrm{~h}$. Of the six patients, two were included in further experiments on the characterization of talc-induced inflammation.

The pleural fluids were stored immediately in plastic containers at $4^{\circ} \mathrm{C}$ and processed within $2 \mathrm{~h}$ after collection. Cells were counted and collected via centrifugation, and cytospin slides were made. The supernatants of the pleural fluids were stored in portions at $-80^{\circ} \mathrm{C}$. To assess dilution with saline caused by the pleural washing or by the installation of talc slurry, urea was determined in the pleural fluids and in blood plasma. The chemokine concentrations and the measured concentrations and cell indices of total cell counts were corrected by the dilution factor (plasma urea/pleural fluid urea) [11].

Cell staining was performed with May-Grünwald Giemsa and cell differentiation was conducted by counting 200 cells per slide. MCP-1 and IL-8 concentrations were measured by sandwich enzyme-linked immunosorbent assay (ELISA). The MCP-1 ELISA was developed in the authors' laboratory and showed no crossreaction with other chemokines (detection level $30 \mathrm{pg} \cdot \mathrm{mL}^{-1}$ ) [12]. The commercial IL-8 ELISA had a detection level of $40 \mathrm{pg} \cdot \mathrm{mL}^{-1}$ (Pharmingen, San Diego, CA, USA).

\section{Statistical analysis}

All data are expressed as the mean \pm SEM. The median is given when appropriate. Multiple linear regression analysis was used to study the relationship between the continuous variables "time after talc administration", cell kinetics and chemokine concentrations (logarithmic values). Differences between the patient groups were evaluated using the Student's t-test. A p-value $<0.05$ was considered to indicate statistical significance.

\section{Results}

In total, 53 samples were collected in the ISP group and 28 in the MPE group. In the MPE group, the inflammation in the pleural cavity could be monitored up to $24-48 \mathrm{~h}$ prior to halting the drain production and chest tube removal. In the ISP patients, fluid was collected for up to 72 $\mathrm{h}$ following talc administration.
Table 1. - Influence of the chest tube on the leukocyte count and cell indices in the pleural fluid of patients with idiopathic spontaneous pneumothorax

\begin{tabular}{lccccr}
\hline & \multicolumn{2}{c}{$\begin{array}{c}\text { After installation of } \\
\text { chest tube }\end{array}$} & & \multicolumn{2}{c}{$\begin{array}{c}\text { During VAT } \\
\text { procedure }\end{array}$} \\
\cline { 2 - 3 } \cline { 5 - 6 } & $\begin{array}{c}\text { Leukocyte } \\
\%\end{array}$ & Median & & $\begin{array}{c}\text { Leukocyte } \\
\%\end{array}$ & Median \\
& $4.5 \pm 1.0$ & 3.8 & & $8.2 \pm 3.0$ & 7.9 \\
Leukocytes* & $47.1 \pm 15.4$ & 59.0 & & $35.2 \pm 11.1$ & 26.5 \\
PMN & $26.1 \pm 9.7$ & 20.3 & & $42.4 \pm 10.9$ & 44.0 \\
Macrophages & $2.5 \pm 1.8$ & 2.0 & & $5.0 \pm 2.4$ & 3.5 \\
Lymphocytes & $3.8 \pm 12.8$ & 9.2 & & $16.4 \pm 9.0$ & 10.5 \\
\hline Eosinophils & $22.8 \pm 12.0$ &
\end{tabular}

Values are expressed as mean \pm SEM. *: absolute number $\times 10^{6}$. The cell counts are corrected for dilution. The percentage of other cell types such as mesothelial cells and basophils was always $<1 \%$. VAT: video-assisted thoracoscopy; PMN: polymorphonuclear neutrophils. None of the differences were statistically significant (Student's t-test; $\mathrm{n}=6$.)

Pilot experiment: influence of chest tube on the inflammatory process in the pleural cavity

To study the influence of the chest tube on the inflammatory process in pleural fluids from six ISP patients, samples were taken immediately after the installation of the tube and during the VAT procedure just before talc administration. Table 1 shows the cellular differentiation and the cell count. While the tube was present, the cell number showed a minor but nonsignificant increase over a period of $34 \pm 9 \mathrm{~h}(\mathrm{p}=0.33)$. Only small differences in cellular differentiation were noted. It was concluded that the chest tube did not have a major influence on the inflammatory process in the pleural cavity.

\section{Cell differentiation in the pleural fluid after talc adminis-} tration

Talc administration induced a short fall in the leukocyte concentration, maximal after 3-6 h. This was followed by a marked increase after 6-48 h (table 2). Maximal cell counts were reached 1-2 days following talc administration, after which the number slowly declined (data not available for MPE). A large interindividual variation was found in the total cell numbers in the pleural fluids, especially in the ISP group. The absolute cell numbers were almost always higher in the ISP group. The cell indices, directly proceeding from the start of the treatment, differed between both patient groups (fig. 1). Pleural fluid of

Table 2. - Leukocyte influx in pleural fluids in response to talc administration

\begin{tabular}{|c|c|c|c|c|c|c|}
\hline \multirow[b]{2}{*}{$\begin{array}{l}\text { Time } \\
\text { after } \\
\text { talcage } \mathrm{h}\end{array}$} & \multicolumn{3}{|c|}{$\begin{array}{l}\text { Idiopathic spontaneous } \\
\text { pneumothorax }\end{array}$} & \multicolumn{3}{|c|}{$\begin{array}{l}\text { Malignant pleural } \\
\text { effusion }\end{array}$} \\
\hline & $\mathrm{n}$ & $\begin{array}{c}\text { Leukocyte } \\
\text { number } \\
\times 10^{6} \cdot \mathrm{mL}^{-1}\end{array}$ & Median & $\mathrm{n}$ & $\begin{array}{l}\text { Leukocyte } \\
\text { number } \\
\times 10^{6} \cdot \mathrm{mL}^{-1}\end{array}$ & Median \\
\hline 0 & 13 & $14.2 \pm 11.4$ & 1.4 & & $0.4 \pm 0.2$ & 0.2 \\
\hline 3 & 10 & $1.8 \pm 0.7$ & 0.6 & & $0.2 \pm 0.1$ & 0.1 \\
\hline 6 & 7 & $5.9 \pm 4.2$ & 0.3 & 0 & $0.6 \pm 0.2$ & 0.5 \\
\hline 24 & 9 & $14.1 \pm 8.8$ & 4.2 & 6 & $1.4 \pm 0.5$ & 1.2 \\
\hline 48 & 6 & $14.5 \pm 12.8$ & 2.1 & 5 & $11.4 \pm 5.9$ & 11.1 \\
\hline 72 & 8 & $3.7 \pm 1.7$ & 1.4 & & $\mathrm{ND}$ & $\mathrm{ND}$ \\
\hline
\end{tabular}

$\overline{\text { Values are presented as mean } \pm \text { SEM. The cell counts are corrected }}$ for dilution. ND: no data. 

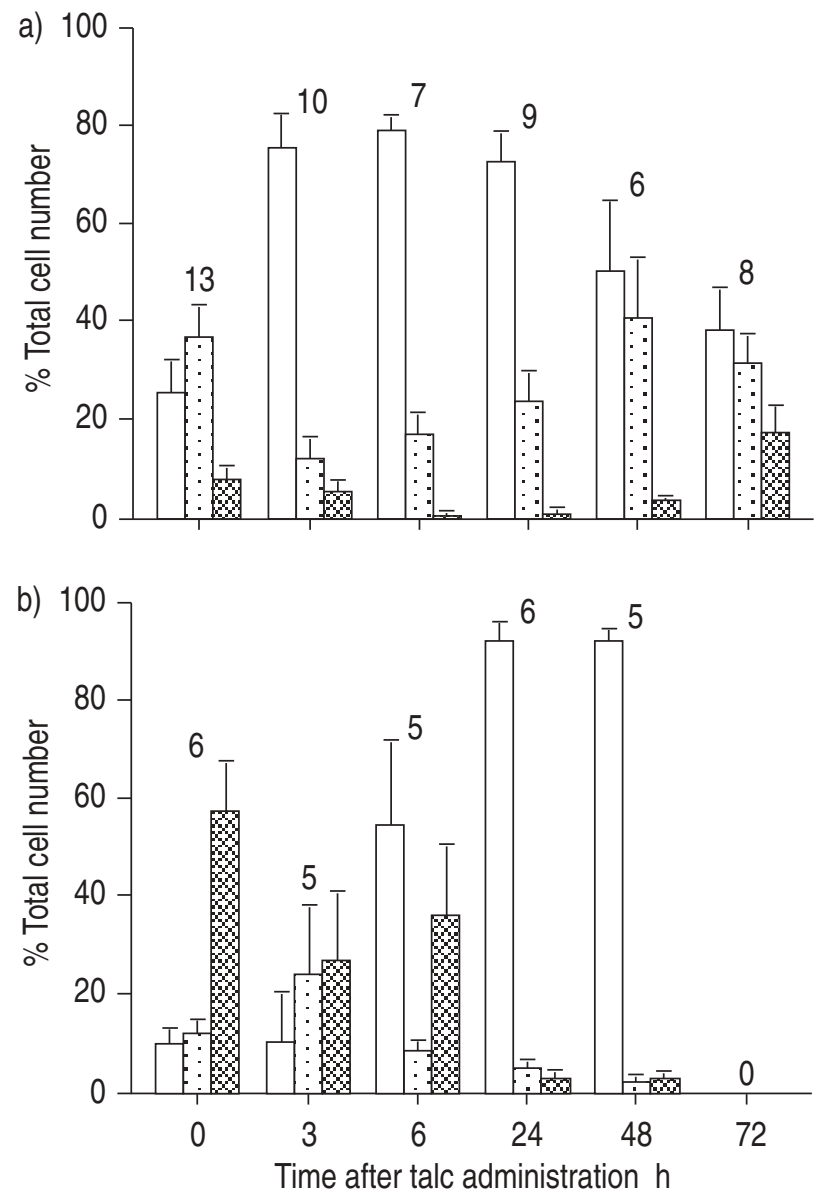

Fig. 1. - Cell kinetics in the pleural fluids after talc administration. Percentages are mean \pm SEM. a) Idiopathic spontaneous pneumothorax; b)

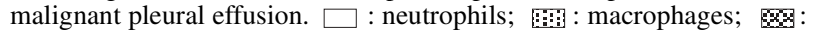
lymphocytes. Numbers above bars represent numbers of patients.

MPE patients contained a considerably higher percentage of lymphocytes, but fewer macrophages, PMN and eosinophils. The percentage of mesothelial cells and tumour cells was always $<1 \%$.

Talc administration induced an inflammatory process characterized by a rapid accumulation of PMNs reaching its maximum after 3-24 h, depending on the patient group, followed by a mononuclear influx after $24 \mathrm{~h}$ depending on the patient group (fig. 1, table 2). In ISP, the PMN percentage peaked very early, after only $3 \mathrm{~h}$. In MPE, it peaked later, at day 1-2.

\section{Chemokines}

The chemokine concentration was calculated by multiplying the measured chemokine concentration by the ureaderived dilution factor. Both the chemokine concentrations as measured by ELISA and the urea dilution factor are given in table 3 . The dilution factor was significantly higher in ISP patients, as could be expected because of the lower spontaneous drain production, but showed no time relation ( $\mathrm{p}=0.04$, Student's t-test).

In both ISP and MPE patients, the IL- 8 and MCP-1 concentrations, corrected for the dilution factor increased with time (fig. 2). On comparing the patient groups, the IL-8 concentration was always higher in pleural fluids from MPE patients, except $3 \mathrm{~h}$ after talcage (fig. 2, table $3)(p<0.05$, Student's t-test). No difference in MCP-1 concentration was detected.

\section{Relation between chemokines and cell indices}

The logarithmic value of the IL- 8 concentration was related to the percentage of PMNs $(r=0.32, p=0.006)$ (fig. 3 ) and this was mainly due to the MPE group, which showed a strong correlation between the IL- 8 concentration and the PMN percentage $(r=0.52, p=0.007)$. In the ISP group the relationship did not reach statistical significance $(\mathrm{r}=0.25, \mathrm{p}=0.08)$. The MCP-1 concentration showed a weak and negative relationship with the percentage of macrophages $(\mathrm{r}=-0.27, \mathrm{p}=0.024)$ (fig. $3 \mathrm{~b})$. This association was lost when the two patient groups were analysed separately (ISP: $\mathrm{r}=-0.17, \mathrm{p}=0.24$; MPE: $\mathrm{r}=-0.094, \mathrm{p}=0.66$ ). Even when data from the first $6 \mathrm{~h}$ were excluded, no positive relation was detected $(\mathrm{r}=-0.052, \mathrm{p}=0.78)$.

Other cell types were not linked to chemokine concentrations. Furthermore, when absolute cell numbers were calculated any associations with the chemokine concentrations were lost.

\section{Discussion}

To the authors' knowledge this is the first study to correlate the cellular kinetics with the concentration of chemokines in the pleural cavity during an acute inflammatory response. The data show that this talc-induced inflammation is characterized by an influx of PMN, followed by an accumulation of macrophages. A similar inflammatory pattern was found in talc-induced pleurodesis in several

Table 3. - Measured interleukin (IL)-8 and monocyte chemotactic factor (MCP)-1 concentrations and dilution factors in pleural fluids

\begin{tabular}{|c|c|c|c|c|c|c|c|c|}
\hline \multirow[b]{2}{*}{$\begin{array}{l}\text { Time after } \\
\text { talcage } \mathrm{h}\end{array}$} & \multicolumn{4}{|c|}{ Idiopathic spontaneous pneumothorax } & \multicolumn{4}{|c|}{ Malignant pleural effusion } \\
\hline & $\mathrm{n}$ & $\begin{array}{l}\text { Dilution } \\
\text { factor }\end{array}$ & $\begin{array}{l}\mathrm{MCP}-1 \\
\mathrm{ng} \cdot \mathrm{mL}^{-1}\end{array}$ & $\begin{array}{c}\mathrm{IL-8} \\
\mathrm{ng} \cdot \mathrm{mL}^{-1}\end{array}$ & $\mathrm{n}$ & $\begin{array}{c}\text { Dilution } \\
\text { factor }\end{array}$ & $\begin{array}{l}\mathrm{MCP}-1 \\
\mathrm{ng} \cdot \mathrm{mL}^{-1}\end{array}$ & $\begin{array}{c}\text { IL-8 } \\
\mathrm{ng} \cdot \mathrm{mL}-1\end{array}$ \\
\hline 0 & 13 & 4.1 & 0.26 & 0.01 & 6 & 1.7 & 3.1 & 0.15 \\
\hline 3 & 10 & 3.4 & 3.7 & 0.20 & 5 & 1.3 & 5.5 & 0.55 \\
\hline 6 & 7 & 18.2 & 0.45 & 0.11 & 6 & 1.3 & 22.3 & 42.5 \\
\hline 24 & 9 & 3.1 & 1.0 & 0.11 & 6 & 1.2 & 7.7 & 57.4 \\
\hline 48 & 6 & 9.4 & 0.37 & 0.08 & 5 & 2.7 & 7.6 & 20.1 \\
\hline 72 & 8 & 1.6 & 0.81 & 0.13 & 0 & $\mathrm{ND}$ & ND & ND \\
\hline
\end{tabular}

Values represent median concentrations measured by enzyme-linked immunosorbent assay (ELISA). The chemokine concentrations can be obtained by multiplying the measured concentration by the corresponding dilution factors. ND: no data. 

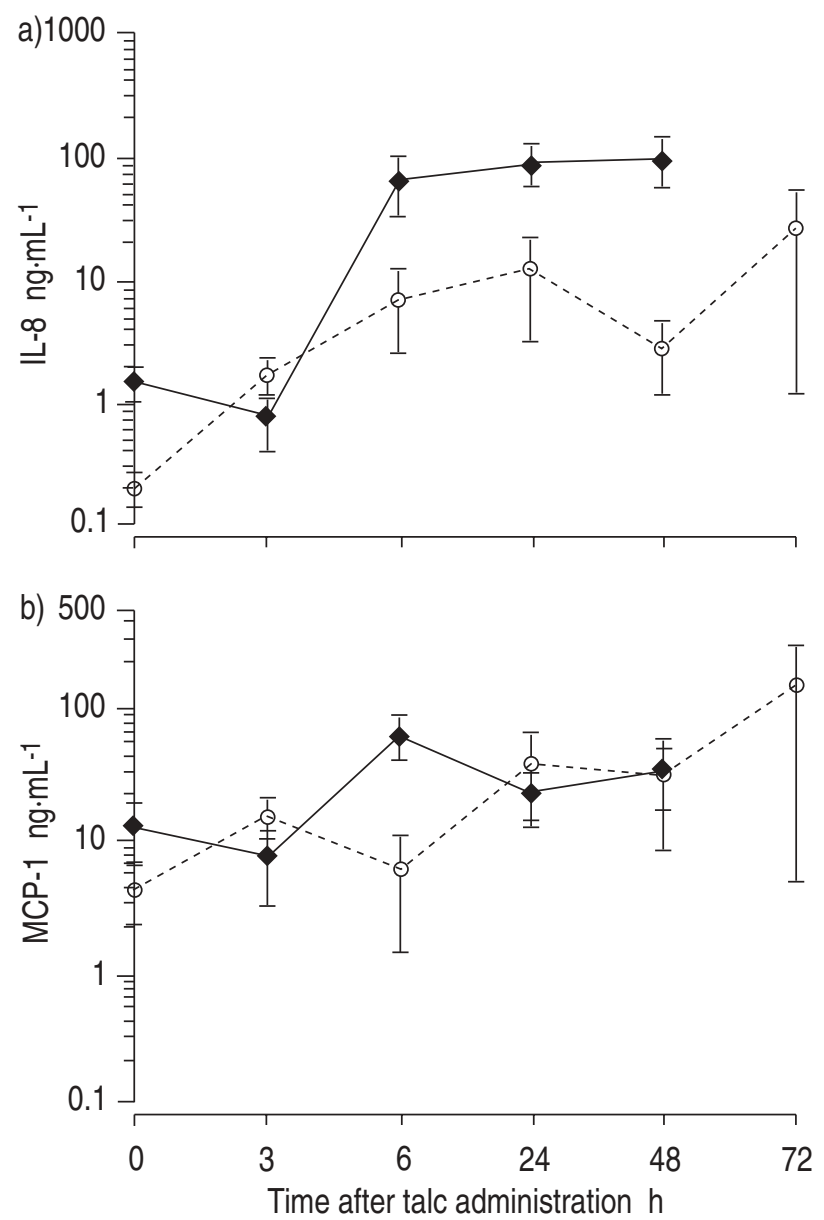

Fig. 2. - Chemokine concentrations in the pleural fluid of idiopathic spontaneous pneumothorax (ISP, O) and malignant pleural effusion $(\mathrm{MPE}, \diamond)$ patients related to time after talc administration. a) Interleukin-8 (IL-8) (MPE: r=0.62, p<0.001; ISP: $r=0.27$, p=0.06); b) monocyte chemotactic protein-1 (MCP-1) (MPE: $r=0.40, p<0.05$; ISP: $\mathrm{r}=0.19, \mathrm{p}=0.17)$. The chemokine concentration in the pleural fluids was corrected for dilution.

animal models [13-15]. It has been suggested that IL-8 and MCP-1 are involved in the chemoattraction of the $\mathrm{PMN}$ and monocytes in the pleural cavity [9]. The present data on IL-8 are in concordance with this hypothesis. In the MPE group, IL-8 production preceded the PMN influx

and the IL-8 concentration was strongly correlated to the PMN percentage in the pleural fluid. In the ISP group, however, the relation was much weaker. Several explanations can be given for this difference. Firstly, in the ISP group a plateau was reached in the percentage of PMN in the pleural fluid after only $3 \mathrm{~h}$. To study the relation between IL-8 and such a rapid PMN influx more fluid samples would need to have been collected in the first hours after talc administration. In the MPE group, the PMN accumulation followed a slower course and therefore sampling was adequate. Secondly, the absolute IL-8 concentrations were much lower in the ISP group, sometimes close to the detection level of the ELISA. This might have influenced the accuracy of the test. Thirdly, it cannot be excluded that other chemokines are also involved in the PMN attraction.

For MCP-1 the relation with macrophages was much weaker. Macrophage influx is normally a late event in the
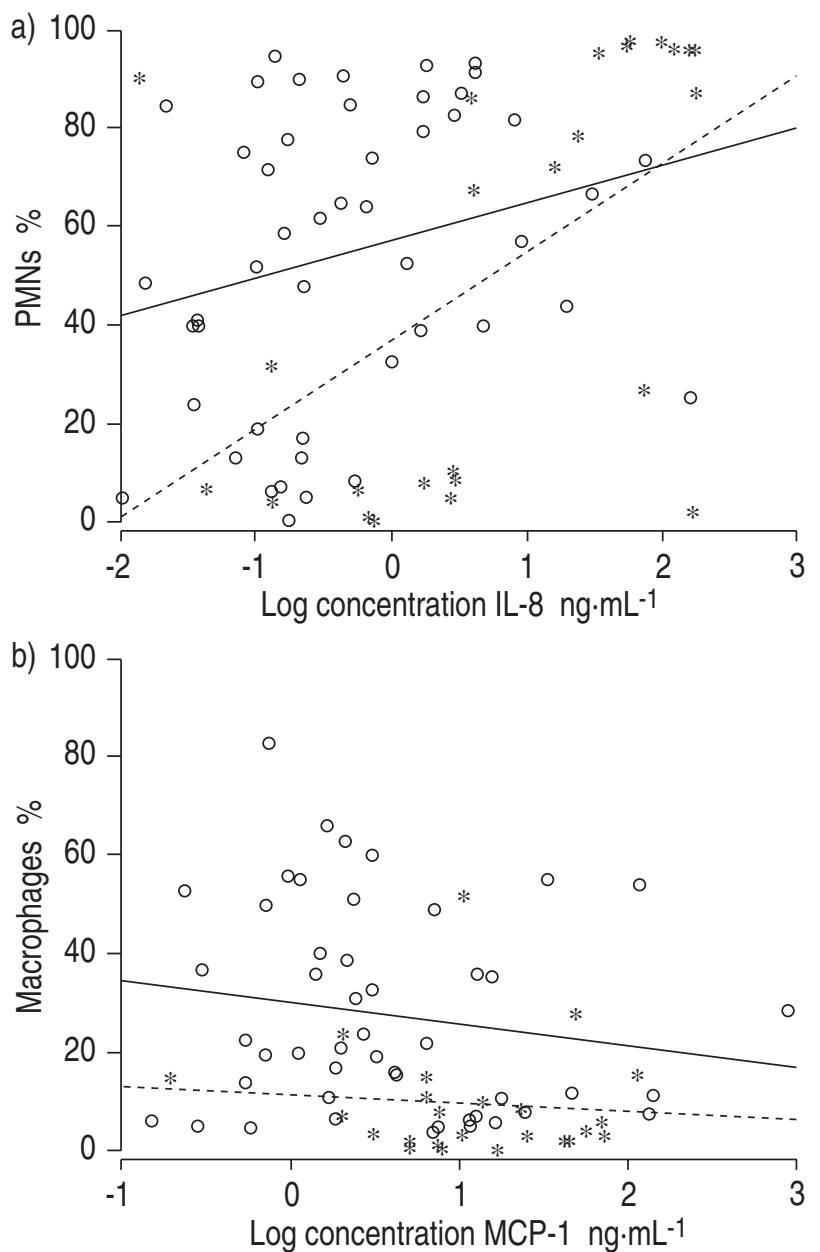

Fig. 3. - Correlation of the cell percentages with the chemokine concentrations in pleural fluid. The concentration of a) interleukin-8 (IL-8) in relation to the percentage of polymorphonuclear neutrophils (PMNs) and b) monocyte chemotactic protein-1 (MCP-1) in relation to the percentage of macrophages are given. $\bigcirc,-$ : idiopathic spontaneous pneumothorax patients; ${ }^{*},-\cdots$ : malignant pleural effusion patients.

inflammatory response, only starting after day $1-2$, and in this study an increase in macrophage number was only seen after $48 \mathrm{~h}$. The fluid production, however, stopped after 23 days and additional samples were not obtained. Therefore, macrophage influx could not be monitored further. Another reason for the lack of association is the high background concentration of MCP-1, which makes statistical analysis more difficult. Furthermore, it has been shown in other studies that despite the lacking of an in vivo correlation between macrophage number and MCP-1 concentration, in vitro blocking experiments have shown MCP-1 to be the chemoattractant agent responsible [12].

Several cells can be held responsible for the chemokine production. IL- 8 can be produced in large quantities by macrophages, but PMNs can also produce small amounts $[16,17]$. Another candidate is the mesothelial cell. Recent studies have shown that mesothelial cells are fairly good producers of IL- 8 after in vitro talc and bacteria phagocytosis $[18,19]$. It is likely that both the mesothelial cell and the macrophage are responsible for the talc-induced chemokine production, whereas in MPE patients malignant cells may also play a role in MCP-1 production [9]. 
In both patient groups the leukocyte traffic followed a similar sequence. An initial decrease in cell number was followed by a restoration after $6 \mathrm{~h}$, after which the number increased steeply. The initial decrease might be explained by either toxic effects of the talc on the leukocytes or adherence of the activated leukocytes to the inner layer of the pleural cavity. It is unknown whether certain types of leukocytes are more sensitive to talc or other pleurodesisinducing agents in vivo. Preferential adhesion or cell death of certain cell types might obscure the total number of leukocytes present in the pleural cavity. For this reason one must be extra critical in interpreting data on leukocyte number and cell indices in the pleural fluid.

Even though the patient groups showed many distinctions, the differences in the response to talc administration deserve extra attention. As the percentage of PMNs had already reached its maximum in ISP patients after 3-6 h, the process of chemoattraction had to begin almost immediately after talc insufflation. In the pleural fluids of MPE patients, the cell kinetics followed a less dramatic course, but the percentage of PMNs reached almost $100 \%$ after 24 h. Several explanations can be postulated for the slower cellular reaction to talc in the pleural cavity of MPE patients. Firstly, the larger number of phagocytes in the pleural cavity of ISP patients, just before talcage, could induce a more rapid inflammatory response. Activation of macrophages and PMNs by phagocytosis induces rapid secretion of several mediators such as pro-inflammatory cytokines along with chemokines that can accelerate the inflammatory response. A second explanation lies in the obvious distinctions between patient groups (e.g. pleural disease, age and immune status). Thirdly, the talc administration procedure may play a role. Administration of dry talc powder directly to the whole "dry" pleural surface may induce more rapid chemokine production than talc slurry via a chest tube on a "wet" pleural surface. Further studies are required to compare the efficacy of both these talc procedures and to correlate it with the inflammatory indices in an otherwise comparable patient group.

The data presented shows that talcage induces a dramatic inflammatory response, whereas drainage alone causes only minor differences in the pleural fluid. This might explain why talcage is more effective than drainage in inducing pleurodesis. Similar studies on the cellular and chemokine composition of pleural fluids can be used to assess the effectivity of pleurodesis by other agents. It can be hypothesized that agents which induce chemoattraction and activation of monocytes and PMNs can also cause an effective pleurodesis. A more detailed insight in the mechanism could help in the design of a less painful, yet equally effective treatment.

In conclusion, this study describes the inflammatory reaction in the pleural cavity after talcage in two different patient groups. It clearly shows the time-related accumulation of polymorphonuclear neutrophils and macrophages. The concentration of interleukin- 8 increases with time and is correlated with the influx of polymorphonuclear neutrophils. The data suggest that either the underlying disease or the method of talc administration may influence the inflammatory process.

Acknowledgements: The authors wish to thank the Clinical Chemistry Dept of the Vrije University Hospital Amsterdam for determining the urea concentrations and
A. Mantovani for providing the anti-MCP-1 monoclonal antibody 5D3-F7 used in the MCP-1 ELISA. The authors are indebted to the nursing staff of the Dept of Pulmonary Medicine in the Vrije University Hospital Amsterdam, The Netherlands.

\section{References}

1. Schramel FMNH, Postmus PE, Vanderschueren RGJRA. Current aspects of spontaneous pneumothorax. Eur Respir J 1997; 10: 1372-1379.

2. Walker-Renard PB, Vaughan LM, Sahn SA. Chemical pleurodesis for malignant pleural effusions. Ann Intern Med 1994; 120: 56-64.

3. Light RW. Malignant pleural effusions. In: Pleural Diseases, 3rd Edn. Baltimore, MD, Williams \& Wilkins, 1995; pp. 94-116.

4. Aelony Y, King R, Boutin C. Thoracoscopy talc poudrage for chronic recurrent pleural effusions. Ann Intern Med 1991; 115: 778-782.

5. Vargas FS, Milanez JRC, Filomeno LTB, Fernandez A, Jatene A, Light LW. Intrapleural tale for the prevention of recurrence in benign or undiagnosed pleural effusions. Chest 1994; 106: 1771-1775.

6. Kennedy L, Rusch VW, Strange C, Ginsberg RJ, Sahn SA. Pleurodesis using talc slurry. Chest 1994; 106: 342-346.

7. Baggiolini M, Dewald B, Moser B. Interleukin-8 and related chemotactic cytokines - CXC and CC chemokines. Adv Immunol 1994; 55: 97-179.

8. Zack Howard OM, Ben-Baruch A, Oppenheim JJ. Chemokines: progress toward identifying molecular targets for therapeutic agents. Tibtech 1996; 14: 46-51.

9. Antony VB, Godbey SW, Kunkel SL, et al. Recruitment of inflammatory cells to the pleural space. Chemotactic cytokines IL-8, and MCP-1 in human pleural fluids. $J$ Immunol 1993; 151: 7216-7223.

10. Rodriguez-Panadero F, Antony VB. Pleurodesis, state of the art. Eur Respir J 1997; 10: 1648-1654.

11. Rennard SI, Basset G, Lecossier D, et al. Estimation of volume of epithelial lining fluid recovered by lavage using urea as marker of dilution. J Appl Physiol 1986; 60: 532-538.

12. Tekstra J, Visser CE, Tuk CW, et al. Identification of the major chemokines that regulate cell influxes in CAPD patients. J Am Soc Nephrol 1996; 7: 2379-2384.

13. Bethune N. Pleural poudrage: a new technique for the deliberate production of pleural adhesions as a preliminary to lobectomy. J Thorac Surg 1935; 4: 251-261.

14. Hanrahan EM, Adams R, Klopstock RJ. The role of experimentally produced intrapleural adhesions in extrapleural pneumonolysis and in the prevention of surgical atelectasis in animals. J Thorac Surg 1941; 10: 284-299.

15. Singer JJ, Jones JC, Tragerman LJ. Aseptic pleuritis experimentally produced. J Thorac Surg 1941; 10: 251-283.

16. Cassatella MA. The production of cytokines by polymorphonuclear neutrophils. Immunol Today 1995; 16: 21-26.

17. Adams DH, Lloyd AR. Chemokines: leukocyte recruitment and activation cytokines. Lancet 1997; 249: 490-495.

18. Hartman DL, Gobley SW, Lu L. Talc stimulates interleukin-8 (IL-8) release by human pleural mesothelial cells (HPMC) in vitro. Am Rev Respir Dis 1993; 147: A797 (Abstract).

19. Visser CE, Brouwer-Steenbergen JJE, Betjes MGH, et al. IL-8 production by human mesothelial cells after direct stimulation with staphylococci. Infect Immun 1995; 63: 4206-4209. 